УДК 1

DOI $10.21661 / \mathrm{r}-117811$

\title{
Н.В. Власова
}

\section{ПСИХОЛОГО-ПЕДАГОГИЧЕСКОЕ ИССЛЕДОВАНИЕ ЦЕННОСТНЫХ ОРИЕНТАЦИЙ СОВРЕМЕННОГО ЮНОШЕСТВА}

Аннотация: статья посвящена анализу проведенного психолого-педагогического исследования формирования изенностных ориентаџий в разные возрастные периодыл. В данной работе рассматриваются различные подходы в изучении развития и принятия цеенностей в детском, подростковом и юношеском возрасте. Приведены как ранговые оценки предпочтений цеенностей в разные жизненные периоды, так и качественный анализ этих цуенностей на каждом возрастном этапе формирования и становления личности.

Ключевые слова: психолого-педагогическое исследование, ценностные ориентацчии, ценность, потребности, превентивные меры, качественные и количественные показатели.

\section{N.V. Vlasova}

\section{PSYCHOLOGICAL AND PEDAGOGICAL RESEARCH OF MODERN YOUNG PEOPLE VALUES}

Abstract: this article is based on the psycho-pedagogical research of values orientation formation in different age groups. This research touches upon diverse approaches to values development and acceptance among children, teenagers and youngsters. This article adduses quantitative analysis of values preferences in different periods of life as well as qualitative analysis of these values in each age group.

Keywords: psycho-pedagogical research, values orientation, value, needs, preventive measures, qualitative and quantitative indexes.

В настоящее время проблема изучения ценностных ориентаций молодежи, жизненного и профессионального выбора, а следовательно, и психологическое 
самоопределение юношей, становится наиболее актуальной. Ценностные ориентации молодых людей отражаются в их взглядах и отношении к себе и окружающим, а это влияет на их общую манеру поведения и действия, их жизненные установки, стремления. Это по сути определяет, в каком направлении двигается молодое поколение, к чему стремится и как реализует свою жизненную программу.

Предмет изучения жизненных смыслов и ценностной ориентации молодежи представляется особенно важным, учитывая рост преступлений, совершенных подростками и юношами в соотношении с общими показателями криминала, связи с постоянно возрастающей нагрузкой на интеллектуальную, духовную и деятельностную сферу современных молодых людей. В последние несколько лет происходит общее омоложение среди лиц, демонстрирующих социо-патологическое поведение во время образовательного процесса в школе, нередки случаи крайней жестокости и агрессии по отношению как к сверстникам, так и к старшему поколению. Необходимо отметить, что профилактика такого социо-патологического поведения является более эффективным и экономичным методом, чем попытки его устранения или борьбы с ним.

Таким образом, образовательное учреждение и его влияния в общекультурном процессе играет важную роль в первичном предотвращении, а поведение и влияние педагогов может быть превентивной мерой, которая может предотвратить развитие криминальности среди детей и молодежи посредством влияния на их ценности и ценностную ориентацию. Следование элементарным моральным принципам представляет собой базовые, универсальные надкультурные ценности: уважение, благородство, сострадание, честь, достоинство, толерантность, взаимопомощь, послушание, честность, открытость, широта взглядов, порядочность, ответственность, самоконтроль, и др.»

Образовательный процесс как в школе, так и в высшем учебном заведении играет большую роль в формировании ценностных предпочтений и ценностной ориентации. Для того чтобы эффективно влиять на процесс формирования цен- 
ностных ориентаций молодежи, необходимо знать те ценности, которые являются на сегодняшний день наиболее предпочтительными для детей и юношества, т.е. на те из них, которые считаются значимыми в разные периоды формирования личности.

В ходе проведенного нами исследования мы основывались на том, что нас в большей степени интересует как процесс формирования ценностных ориентаций, так и изменение их в течении периода от детства к юношеству, а также значение, позиция и роль образования в процессе формирования ценностей и ценностных ориентации детей и молодежи.

В исследовании мы выявили, какие в настоящее время сформированы предпочтения в ценностных ориентациях детей, подростков и молодежи. В чем их разница, как варьируются они в зависимости от возрастной группы и что оказывает наиболее существенное влияние на их формирование.

Психолого-педагогическое исследование проводилось в нескольких образовательных учреждениях города Москвы. Общее количество респондентов 959 человек. Основываясь на типах вопросов, респонденты были распределены на 3 категории: первая - ученики начальных классов общеобразовательных школ (321 человек); 2 категория - ученики старших классов общеобразовательных школ (312 человек) и последняя категория, это студенты психологических факультетов московских вузов (326 человек).

В процессе исследования были выявлены те категории ценностей, которые в настоящее время наиболее предпочтительны для респондентов. В связи с чем, были выделены следующие категории ценностей, которые получили наиболее высокие оценки со стороны всех групп респондентов. Такими ценностями оказались следующие.

Образовательные ценности, включающие в себя положительное восприятие образования и знаний, как позитивного аспекта в жизни каждого человека в тех социальных условиях, в которых он находится, а также важность аспекта предполагаемой или желаемой работы, возможный уровень профессиональной самореализации, нацеленной на адекватный характер качества жизни. 
Эстетические ценности, выражающиеся в чувстве прекрасного, красоты природы и искусства. При этом положительное отношение к искусству было напрямую связано с возможностью или попыткой развивать свои эстетические способности и делать свою жизнь и окружение красивее, самостоятельное развитие культуры и сохранение культурно-исторического наследия нации.

Моральные ценности трактовались, как нацеленность на стремление человека совершать позитивные, социально одобряемые поступки, помогать, сотрудничать. Важным аспектом являлись такие глубинные ценности и возможности их удовлетворять, как альтруизм, способность прийти на помощь, защитить слабого, проявлять честность и принципиальность в различных сферах своей жизнедеятельности.

Финансовые ценности рассматривались, прежде всего, как умение рационально и эффективно сохранять, накапливать приемлемое количество финансовых средств, что ведет к удовлетворению материальных и духовных потребностей.

Социальные ценности напрямую были связаны с активной социальной жизнью в условиях привычного окружения, характеризующиеся стремлением справляться с возникающими в области различных видов коммуникации трудностями, стремление с интересом контактировать с другими, а также высоким социальным чувством, эмпатией, стремлением сочувствовать и сопереживать.

Исходя из полученных нами данных, однозначно можно сделать вывод о том, что дети младшего школьного возраста предпочитают социальные ценности. Видимо, что это предпочтение вызвано периодом детства, когда дети начинают постепенно сепарироваться от родителей и адаптируются в новой школьной среде, где ищут межличностный контакт, дружбу. Данное исследование подтверждается также и в работе Е.Л. Буслаевой [2]. Предпочтение социальных ценностей также является следствием позитивного авторитета родителя, учителя и других взрослых. Определенное позитивное отношение к социальным ценностям значимого взрослого, вызывающего у ребенка авторитет, настраивает ре- 
бенка на приобретение позитивного социального опыта. Также можно предположить, что этот авторитет взрослого и сам по себе показывает высокую степень важности социальных ценностей в жизни человека вообще.

На втором месте оказалась категория образовательных ценностей. Важность этих ценностей возрастает, в тот момент, когда дети начинают самостоятельно осознавать ценность образовательного процесса. Позитивно на формирование данных ценностей влияют и положительные оценки по предметам, изучаемым ребенком. Отметим, что предпочтение образовательной ценности был выше у тех детей, которые показывали высокую успеваемость. Также образовательные ценности предпочитают и те, из детей, в семьях которых родители поддерживают интерес ребенка к процессу обучения, демонстрируют ему свою заинтересованность в его профессиональном будущем.

Менее предпочтительными оказались моральные, экономические и эстетические ценности. Этот факт объясняется тем, что формирование ценностных ориентаций в этом возрасте находится только в начале своего развития. Ребенок еще соблюдает общепринятые нормы и правила исходя не из собственного мнения и поведения, а потому, что к этому постоянно его призывают значимые близкие - учителя, родители.

Некоторым образом ожидание высоких показателей по формированию и предпочтению финансовых ценностей в ходе исследования не оправдались, видимо это результат того, что сейчас возрастают стандарты экономического благосостояния семьи, а кроме этого в исследовании не принимали участия дети из семей с очень высоким и очень низким уровнем материального благополучия.

Еще меньший результат получили предпочтения эстетических ценностей, но формирование этих ценностей заметно выше у детей, занимающимися в различных школах искусств, рисования и прикладного ручного труда.

Во 2 категории - подростки, были получены следующие результаты. Сравнивая данные полученные в ходе исследования, можно отметить, что относительно ценностных предпочтений детей, мы видим схожие показатели. Под- 
ростки также предпочитают в основном предпочитают социальные и образовательные ценности. Однако при примерно равной количественной оценке, качественная оценка в этой возрастной группе существенно отличается. Социальные ценности подростков связаны, прежде всего, с удовлетворением потребности в аффилиации, а выражаются главным образом через их отношение к сверстникам. Главным ориентиром здесь становится чувство дружбы, поддержки, взаимопонимание и принятие подростка определенной группой, которая вызывает у него авторитет и уважение. При этом эта группа может быть как социально позитивной, так патосоциальной направленности. Подростки удовлетворяют в группе свои базовые психологические потребности - это потребность в стимуляции, направленности, в осмысленном обучении, эмоциональной стабильности и потребности в получении знаний. Приведенные данные также подтверждаются ранее проводимыми в этой области исследованиями, например, это вопрос довольно хорошо освещен в работах В.С. Агапова [1].

Выбор образовательных ценностей по нашему мнению оказался заметно высок в этой возрастной группе в следствие позитивного влияния определенных образовательных факторов, скорее всего личности учителя, авторитет к которому был сформирован ранее. Тот факт, что образовательные ценности были высоко оценены подростками, как правило, результат уже сформированной ценности получения высокого образования, желания хорошо окончить школу, поступить в престижный вуз, который в дальнейшей жизни подростка выступает как средство получения конкурентной профессии, социального престижа. Порядок распределения других ценностных категорий также является результатом влияния окружения, который демонстрирует очевидные предпочтения экономических ценностей, что активно продвигается информацией масс медиа. Невысоки и результаты предпочтения моральных ценностей среди подростков. Формирование морали и нравственности на этом возрастном этапе идет довольно сложным, а часто и ошибочным путем. В этот период уже подросший ребенок только пробует насколько важным является соблюдение принятых в обществе норм. Он довольно критичен по отношению к нравственным эталонам общества. В этот 
период подросток только начинает осознавать ценность таких моральных ценностей как справедливость, правдивость, доверие и др. Примерно таков же результат и предпочтения эстетических ценностей. По сравнению с периодом детства этот показатель в подростковом возрасте становится заметно выше, хотя и занимает также последнее место в сфере направленности подростка. Однако влияние информации и личный интерес подростка к своему внешнему виду, желание произвести нужное впечатление на окружающих является основным фактором формирования эстетической ценности.

И, наконец, рассмотрим третью категорию - молодежь, студенты. По результатам проведенного психолого-педагогического исследования в этой возрастной группе происходит сдвиг в пользу моральных ценностей, которые существенно превосходят экономические и эстетические. Социальные и образовательные ценности также находятся на первом и втором месте, но разница между ними гораздо меньше, чем в других категориях. Предпочтение социальных ценностей, с одной стороны, связано с выполнением социальных потребностей по средствам создании новых отношений и попытками найти свое место в новом социальном окружении, умением выступать в разных ролях, в которых им нужно выполнить и удовлетворить определенные ожидания, связанные с этими социальными ролями. Следствием удовлетворения этих ожиданий является предпочтение образовательных ценностей, т.к. новая роль студента университета, является новой ролью развивающейся личности на ее пути к профессиональной готовности к будущей работе. Следовательно, можно сделать вывод, что реализация социальных потребностей напрямую связанна с получаемой профессией, представлением студента о его будущей специфике деятельности, и о той социальной роли которая потребуется от него в случае становления компетентным специалистом. Также, выбор конкретной учебной программы, предпочтение того или иного профессионального самоопределения диктует и другие ценностные предпочтения, что в основном и является причиной сдвига предпочтения моральных ценностей. Схожие результаты исследования можно найти в рабо- 
тах А.А. Деркача [4] и А.В. Гагарина [3]. Экономические и эстетические ценности получили довольно высокие оценки, но несколько ниже предыдущих и ранее уже описанных нами ценностей в этой возрастной группе. Таким образом, можно сделать вывод о том, что в юношеском возрасте заканчивается период формирования основных жизненных ценностей, происходит личностное и профессиональное созревание. К этому времени человек отличается уже довольно развитой и разветвленной системой ценностей, влияние на которую оказывать довольно сложно.

Подводя итоги исследования, хотелось бы отметить, что учитывая качественное формирование ценностных ориентаций молодежи можно воздействовать на них путем превентивных мер, и делать это необходимо начиная с детского возраста. В этом случае в период юношества человек сформирует позитивные, социально одобряемые ценностные ориентации, которые будут способствовать его продвижению по пути личностного роста, достижению высокого профессионального уровня, стремлению достичь социальной и личностной зрелости.

\section{Сиисок литературы}

1. Агапов В.С. Особенности самооценки в структуре Я-концепции современных подростков / В.С. Агапов // Вестник ГУУ. - 2007. - №7.

2. Буслаева Е.Л. Ценностно смысловые ориентации студентов высшей профессиональной школы / Е.Л. Буслаева // Вестник Оренбургского государственного университета. - 2011. - №2 (121).

3. Гагарин А.В. Образовательная рефлексия в профессиональной подготовке бакалавров психологии / А.В. Гагарин // Акмеология. - 2013. - №3.

4. Деркач А.А. Методологические и прикладные проблемы обучения студентов-психологов / А.А. Деркач // Акмеология. - 2014. - №1.

Власова Наталия Викторовна - канд. психол. наук, доцент НОУ ВО «Столичная финансово-гуманитарная академия», Россия, Москва. 
Vlasova Nataliya Viktorovna - candidate of psychological sciences, associate professor SEI of HE "Capital Financial and Humanitarian Academy”, Russia, Moscow. 